\title{
HUBUNGAN KARAKTERISTIK IBU HAMIL TRIMESTER I DENGAN MORNING SICKNESS DI POLIKLINIK KEBIDANAN DAN PENYAKIT KANDUNGAN BADAN PELAYANAN KESEHATAN RSU DR ZAINOEL ABIDIN BANDA ACEH TAHUN 2007
}

\author{
Relationship Characteristics I Trimester Pregnant Women With Morning Sickness and \\ Disease In Polyclinic Midwifery Content of Health Services Agency RSU Dr Zainoel \\ Abidin Banda Aceh 2007
}

\author{
Suwarni \\ Program Studi Keperawatan Banda Aceh Poli Teknik Kesehatan Departemen Kesehatan \\ Republik Indonesia Nanggroe Aceh Darussalam \\ e-mail: suwarni_nais@yahoo.com
}

\begin{abstract}
ABSTRAK
Karakteristik ibu hamil trimester I terdiri dari umur, banyaknya anak yang dipunyai seorang wanita, berat badan, faktor kepribadian, kebiasaan merokok, ras ibu, pendapatan keluarga dan apakah ibu bekerja di luar rumah atau ibu rumah tangga. Karakteristik tersebut dapat memengaruhi gaya hidup ibu dalam menghadapi hal-hal yang baru termasuk morning sickness yang dialami oleh ibu hamil tersebut. Morning sickness adalah perasaan mual dan muntah pada ibu hamil, biasanya terjadi pada masa 3 bulan pertama kehamilan (trimester pertama). Penelitian bertujuan untuk mengetahui hubungan antara karakteristik ibu hamil trimester I dengan morning sickness di Poliklinik Kebidanan dan Penyakit Kandungan Badan Pelayanan Kesehatan RSU DR Zainoel Abidin Banda Aceh. Desain penelitian bersifat deskriptif korelatif dengan pendekatan cross sectional studi dan menggunakan teknik incidental sampling. Pengumpulan data dilakukan dari tanggal 15-29 Maret 2007 pada ibu hamil trimester I yang berkunjung untuk memeriksakan kehamilannya di Poliklinik Kebidanan BPK RSUZA Banda Aceh terhadap 30 responden ibu hamil. Alat pengumpul data berbentuk kuesioner yang terdiri dua bagian yaitu bagian A berbentuk karakteristik ibu dan bagian B berbentuk data tentang morning sickness. Lembar kuesioner disusun dalam bentuk skala dikotomi. Pengolahan data dilakukan dengan menggunakan uji chi-squre secara manual. Berdasarkan hasil penelitian terhadap variabel independen yaitu karakteristik ibu diperoleh hasil umur berada dalam kategori dewasa awal sebanyak 24 orang (80\%), pendidikan berada dalam ketegori tinggi sebanyak 17 orang $(56,66 \%)$, pendapatan berada dalam kategori tinggi sebanyak 13 orang $(43,33 \%)$ dan responden dalam kategori bekerja sebanyak 16 orang (53,33\%). Gambaran variabel dependen morning sickness diperoleh hasil dalam kategori tidak morning sickness yaitu 19 orang (63,33\%). Dari pengolahan data maka kesimpulan penelitian diperoleh hasil bahwa tidak ada hubungan yang bermakna antara pendidikan dan pendapatan ibu hamil trimester I dengan morning sickness serta ada hubungan yang bermakna antara umur dan pekerjaan ibu hamil trimester I dengan morning sickness di Poliklinik Kebidanan BPK RSUZA Banda Aceh 2007. Peneliti mengharapkan agar perawat memberikan informasi selengkapnya kepada ibu hamil trimester I morning sickness.
\end{abstract}

Kata kunci: karakteristk ibu hamil trimester I, morning sickness.

\section{ABSTRACT}

The characteristics of trimester I of pregnant mother are consisted of age, how many childs a woman have, body weight, personality factors, smoking habit, ethnic, income and job. This characteristics can influences to the mother life style in faces the new things include morning sickness that happen by mother pregnant. Morning sickness is a feel of nauseated and vomited in pregnant, usually happened on first trimester. The purpose of the research design is ascertaining relations of characteristics of trimester I of pregnant mother with morning sickness in obstetric and gynecologic disease policlinic of Bodies of Health Service General Hospital of dr. Zainoel Abidin Banda Aceh. The research design is descriptively correlatively with cross sectional study approach and use the sample collection technique of incidental sampling. Data collecting was conducted from March 15 th to 29th 2007 in obstetric and ginecologic disease policlinic of Bodies of Health Rumah Service General Hospital of dr. Zainoel Abidin Banda Aceh 
for 30 respondents of trimester I of pregnant mother. The data collection device in the form of questionnaire that consisted of two parts namely part $A$ in the form mother characteristics and part B is in form of morning sickness. Sheet of questionnaire was compiled in form dicotomy scale. Data tabulation was conducted used manually chi-square test. Based on the result of the research to the independent variables that is mother characteristics was obtained yields of ages are be in the beginning adults are as much 24 persons (80\%), education is be in high category as much 17 persons (56,66\%), income level is be in high category as much 13 persons (43,33\%) and respondents have a job as much 16 persons (53,33\%). The view of dependent of morning sickness was achieved the yield in no morning sickness category that is 19 persons $(63,33 \%)$. From data tabulation so the the research conclusion are obtained the yields that there is no significant correlation between education and trimester I of mother pregnant income with morning sickness and exist the significant correlation between age and trimester I of mother pregnant job with morning sickness morning sickness in obstetric and ginecologic disease policlinic BPK RSUZA Banda Aceh 2007. The researcher also suggested for the further research to studying the other factors that influences to morning sickness.

Keywords: characteristics of trimester I of pregnant mother, morning sickness

\section{LATAR BELAKANG}

Kesehatan wanita sebagai bagian integral dari perkembangan suatu bangsa, sangat dipengaruhi oleh perkembangan bangsa secara menyeluruh. Peningkatan status kesehatan wanita merupakan komponen penting bagi pembangunan bangsa, baik secara langsung mengkontribusi pada perbaikan ekonomi dan sosial maupun secara tidak langsung melalui kesehatan dan kesejahteraan keluarga yang merupakan kunci utama peningkatan sumber daya manusia (Hamid, 1997). Dalam upaya peningkatan sumber daya manusia sebagai bagian dari upaya membangun manusia Indonesia seutuhnya, pemusatan perhatian terhadap pelayanan kesehatan ibu dan anak menjadi makin penting. Upaya tersebut harus dilakukan sejak hamil sampai ibu melahirkan (Manuaba, 2001).

Kehamilan merupakan suatu peristiwa yang penting dalam kehidupan seorang wanita dan keluarganya. Kehamilan adalah saat terjadinya perubahan fisik ibu, juga saat terjadinya perubahan identitas dan peran setiap orang yaitu ibu, bapak dan anggota keluarganya (Hamilton, 1995).

Kehamilan sering ditandai dengan adanya keluhan mual dan muntah pada awalawal kehamilan, yang disebabkan karena adanya gangguan sistem pencernaan akibat peningkatan asam gastrik dalam lambung sehingga ibu merasa mual dan ingin muntah (Cunningham, 1995). Penyebab yang pasti dari reaksi ini belum ditemukan, tetapi terdapat bukti bahwa mual dan muntah adalah hal yang umum terjadi pada sebagian besar ibu hamil ketika kadar hormon gonadotropin meningkat dan ketika kelenjar endokrin mengalami perubahan drastis (Hamilton, 1995).

Gejala yang disebut morning sickness pada kehamilan ini biasanya terjadi pada pagi hari tetapi menghilang setelah beberapa jam, meskipun kadang kala gejala ini menetap lebih lama dan mungkin terjadi pada waktu lain. Gejala yang menganggu ini biasanya muncul sekitar 6 minggu setelah mulai periode menstruasi terakhir dan biasanya menghilang spontan 6 hingga 16 minggu (Cunningham, 1995). Mual-mual di pagi hari lebih umum daripada di saat yang lain, karena perut mengandung kumpulan asam gastrik yang diendapkan malam hari, saat aktivitas tubuh beristirahat total (Jones, 2005).

\section{METODE}

Penelitian cross sectional study dengan menggunakan desain deskriptif korelatif. Penelitian ini bertujuan untuk memperoleh gambaran hubungan antara karakteritik ibu (umur, pendidikan, pendapatan keluarga dan pekerjaan) dengan morning sickness. 
Partisipan diseleksi dengan menggunakan insidental sampling dengan pertimbangan bahwa populasi ibu hamil trimester I yang berkunjung ke Poliklinik Kebidanan dan Penyakit Kandungan BPK RSUZA Banda Aceh jumlahnya sangat sedikit, dan peneliti menetapkan batas waktu penelitian selama dua minggu kemudian dilanjutkan menggunakan total sampling.

Populasi dalam penelitian ini adalah ibu hamil trimester I yang berkunjung untuk memeriksakan kehamilannya di Poliklinik Kebidanan dan Penyakit Kandungan BPK RSUZA Banda Aceh. Pelaksanaan pengumpulan data penelitian dilaksanakan pada tanggal 15 Maret sampai dengan 29 Maret 2007.

Alat pengumpulan data dalam penelitian ini menggunakan kuesioner, yang terdiri dari dua bagian, yaitu: alat pengumpulan data bagian A, merupakan kuesioner data variabel independen yang akan digunakan untuk mengukur karakteristik ibu hamil trimester I. Alat pengumpulan data bagian B, merupakan kuesioner tentang morning sickness yang terdiri dari 20 pertanyaan. Pertanyaan berbentuk skala dikotomi dengan dua alternatif jawaban, yaitu: "Ya" atau "Tidak", dengan nilai masing-masing 2 = jika "Ya" dan $1=$ jika "Tidak". Dari 18 pertanyaan, yang merupakan pertanyaan positif yaitu nomor: $1,2,3,4,5,7,8,9,10,11,12,13,14,15,17$, 18, 19 dan 20, sedangkan nomor 6 dan 16 merupakan pertanyaan negatif .

\section{HASIL DAN PEMBAHASAN}

\section{Analisa Univariat}

Hasil penelitian terhadap karakteristik ibu hamil trimester I (variabel independen) adalah sebagai berikut:
Tabel 1. Distribusi frekuensi ibu hamil trimester I berdasarkan umur di Poliklinik Kebidanan BPK RSUZA Banda Aceh tahun 2007

\begin{tabular}{llcc}
\hline \multicolumn{1}{c}{ Katagori } & $\begin{array}{c}\text { Frekue } \\
\text { nsi (f) }\end{array}$ & $\begin{array}{c}\text { Persentase } \\
(\%)\end{array}$ \\
\hline $\begin{array}{l}\text { 1. } \\
\text { 2. Msudah (16-20 tahun) }\end{array}$ & 3 & 10 \\
& $\begin{array}{l}\text { Ddewasa awal (21-35 } \\
\text { tahun) }\end{array}$ & 24 & 80 \\
3. & 3 & 10 \\
& $\begin{array}{l}\text { Dewasa pertengahan } \\
\text { (35-45 tahun) }\end{array}$ & & \\
\hline \multicolumn{2}{c}{ Jumlah } & 30 & 100 \\
\hline
\end{tabular}

\section{Pendidikan}

Tabel 2. Distribusi frekuensi ibu hamil trimester I berdasarkan tingkat pendidikan di Poliklinik Kebidanan BPK RSUZA Banda Aceh tahun 2007

\begin{tabular}{llcc}
\hline \multicolumn{1}{c}{ Katagori } & $\begin{array}{c}\text { Frekue } \\
\text { nsi (f) }\end{array}$ & $\begin{array}{c}\text { Persentase } \\
(\%)\end{array}$ \\
\hline 1. $\begin{array}{l}\text { Rendah (SD dan } \\
\text { SLTP) }\end{array}$ & 5 & 16,66 \\
2. Menengah (SLTA) & 8 & 26,66 \\
3. Tinggi (Akademi/PT) & 17 & 56,66 \\
\hline \multicolumn{2}{c}{ Jumlah } & 30 & 100 \\
\hline
\end{tabular}

\section{Pendapatan Keluarga}

Tabel 3. Distribusi frekuensi ibu hamil trimester I berdasarkan tingkat pendapatan keluarga di Poliklinik Kebidanan BPK RSUZA Banda Aceh tahun 2007

\begin{tabular}{lcc}
\hline Katagori & $\begin{array}{c}\text { Frekuensi } \\
\text { (f) }\end{array}$ & $\begin{array}{c}\text { Persentase } \\
(\%)\end{array}$ \\
\hline Rendah & 7 & 23,33 \\
Menengah & 10 & 33,33 \\
Tinggi & 13 & 43,33 \\
\hline \multicolumn{1}{c}{ Jumlah } & 30 & 100 \\
\hline
\end{tabular}

\section{Pekerjaan}

\section{Umur}


Tabel 4. Distribusi frekuensi ibu hamil trimester I berdasarkan tingkat pekerjaan Di Poliklinik Kebidanan BPK RSUZA Banda Aceh tahun 2007

\begin{tabular}{lcc}
\hline Katagori & $\begin{array}{c}\text { Frekue } \\
\text { nsi (f) }\end{array}$ & $\begin{array}{c}\text { Persentas } \\
\mathrm{e}(\%)\end{array}$ \\
\hline $\begin{array}{l}\text { 1. Bekerja (PNS, guru, } \\
\text { swasta, dll) }\end{array}$ & 16 & 53,33 \\
$\begin{array}{l}\text { 2. Tidak bekerja(ibu } \\
\text { rumah tangga) }\end{array}$ & 14 & 46,67 \\
\hline \multicolumn{1}{c}{ Jumlah } & 30 & 100 \\
\hline
\end{tabular}

Hasil penelitian terhadap karakteristik morning sickness adalah sebagai berikut:

Tabel 5. Proporsi ibu hamil trimester I berdasarkan kategori tingkat morning sickness Di Poliklinik Kebidanan BPK RSUZA Banda Aceh tahun 2007

\section{Analisa Bivariat \\ Hubungan Antara Umur Dengan Morning Sicknes}

Tabel 10. Distribusi morning sickness berdasarkan umur Di Poliklinik Kebidanan BPK RSUZA Banda Aceh 2007

\begin{tabular}{|c|c|c|c|}
\hline \multirow{3}{*}{ Umur } & \multicolumn{2}{|c|}{$\begin{array}{c}\text { Tingkat morning } \\
\text { sickness }\end{array}$} & \multirow{3}{*}{ Jumlah } \\
\hline & & Tidak & \\
\hline & M.S & M.S & \\
\hline Dewasa muda & $3(1,1)$ & $0(1,9)$ & 3 \\
\hline Dewasa awal & $8(8,8)$ & $16(15,2)$ & 24 \\
\hline \multicolumn{4}{|l|}{ Dewasa } \\
\hline pertengahan & $0(1,1)$ & $3(1,9)$ & 3 \\
\hline Jumlah & 11 & 19 & 30 \\
\hline
\end{tabular}

\begin{tabular}{|c|c|c|}
\hline Katagori & $\begin{array}{l}\text { Frekuens } \\
\text { i (f) }\end{array}$ & $\begin{array}{l}\text { Persentas } \\
\text { e }(\%)\end{array}$ \\
\hline 1. Morning sickness & 11 & 36,66 \\
\hline $\begin{array}{l}\text { 2. Tidak morning } \\
\text { sickness }\end{array}$ & 19 & 63,33 \\
\hline Jumlah & 30 & 100 \\
\hline
\end{tabular}

Tabel 7. Distribusi ibu hamil trimester I dengan morning sickness berdasarkan umur di Poliklinik Kebidanan BPK RSUZA Banda Aceh tahun 2007

\begin{tabular}{lcccccc}
\hline \multirow{2}{*}{ Umur } & \multicolumn{4}{c}{ Tingkat morning sickness } & \multirow{2}{*}{ Jumlah } \\
\cline { 2 - 6 } & \multicolumn{2}{c}{ M.S } & \multicolumn{2}{c}{ Tidak M.S } & & \\
\cline { 2 - 6 } & $\mathrm{N}$ & $\%$ & $\mathrm{n}$ & $\%$ & $\mathrm{n}$ & $\%$ \\
\hline Dewasa muda & 3 & 10 & 0 & 0 & 3 & 10 \\
Dewasa awal & 8 & 26,66 & 16 & 53,33 & 24 & 80 \\
Dewasa pertengahan & 0 & 0 & 3 & 10 & 3 & 10 \\
\hline \multicolumn{1}{c}{ Jumlah } & 11 & 36,66 & 19 & 63,33 & 30 & 100 \\
\hline
\end{tabular}

Tabel 8. Distribusi ibu hamil trimester I dengan morning sickness berdasarkan tingkat pendidikan di Poliklinik Kebidanan BPK RSUZA Banda Aceh tahun 2007

\begin{tabular}{lcccccc}
\hline \multirow{2}{*}{ Pendidikan } & \multicolumn{3}{c}{ Tingkat morning sickness } & \multicolumn{2}{c}{ Jumlah } \\
& \multicolumn{2}{c}{ M.S } & \multicolumn{2}{c}{ Tidak M.S } & & \\
\cline { 2 - 7 } & $\mathrm{N}$ & $\%$ & $\mathrm{n}$ & $\%$ & $\mathrm{n}$ & $\%$ \\
\hline \multirow{2}{*}{ Rendah } & 3 & 10 & 2 & 6,66 & 5 & 16,66 \\
Menengah & 4 & 13,33 & 4 & 13,33 & 8 & 26,66 \\
Tinggi & 4 & 13,33 & 13 & 43,33 & 17 & 56,66 \\
\hline \multicolumn{1}{c}{ Jumlah } & 11 & 36,66 & 19 & 63,33 & 30 & 100 \\
\hline
\end{tabular}


Tabel 9. Distribusi ibu hamil trimester I dengan morning sickness berdasarkan tingkat pendapatan di Poliklinik Kebidanan BPK RSUZA Banda Aceh tahun 2007

\begin{tabular}{lccccccc}
\hline \multirow{2}{*}{ Pendapatan } & \multicolumn{3}{c}{ Tingkat morning sickness } & \multicolumn{2}{c}{ Jumlah } \\
\cline { 2 - 8 } & \multicolumn{2}{c}{ M.S } & \multicolumn{3}{c}{ Tidak M.S } & & \\
\cline { 2 - 8 } & $\mathrm{n}$ & $\%$ & $\mathrm{n}$ & $\%$ & $\mathrm{n}$ & $\%$ \\
\hline \multirow{2}{*}{ Rendah } & 5 & 16,66 & 2 & 6,66 & 7 & 23,33 \\
Sedang & 3 & 10 & 7 & 23,33 & 10 & 33,33 \\
Tinggi & 3 & 10 & 10 & 33,33 & 13 & 43,33 \\
\hline \multicolumn{1}{c}{ Jumlah } & 11 & 36,66 & 19 & 63,33 & 30 & 100 \\
\hline
\end{tabular}

Tabel 10. Distribusi ibu hamil trimester I dengan morning sickness berdasarkan pekerjaan di Poliklinik Kebidanan BPK RSUZA Banda Aceh tahun 2007

\begin{tabular}{|c|c|c|c|c|c|c|}
\hline \multirow{3}{*}{ Pekerjaan } & \multicolumn{4}{|c|}{ Tingkat morning sickness } & \multirow{2}{*}{\multicolumn{2}{|c|}{ Jumlah }} \\
\hline & \multicolumn{2}{|c|}{ M.S } & \multicolumn{2}{|c|}{ Tidak M.S } & & \\
\hline & $\mathrm{N}$ & $\%$ & $\mathrm{n}$ & $\%$ & $\mathrm{n}$ & $\%$ \\
\hline Bekerja & 2 & 6,66 & 14 & 46,66 & 16 & 53,32 \\
\hline Tidak bekerja & 9 & 30 & 5 & 16,66 & 14 & 46,66 \\
\hline Jumlah & 11 & 36,33 & 19 & 63,32 & 30 & 100 \\
\hline
\end{tabular}

Dari tabel 10 diketahui nilai $\chi^{2}$ hitung adalah 7,52808. Selanjutnya dilakukan pengujian hipotesa dimana tabel dengan $=$ 0,05 dan $\mathrm{df}=2$ adalah 5,991. Perbandingan antara kedua nilai tersebut, diperoleh hasil $\chi^{2}$ hitung $(7,52808)>$ tabel $(5,991)$. Sehingga dapat diketahui bahwa hipotesa kerja (Ho) ditolak yang berarti ada hubungan yang bermakna antara umur ibu hamil trimester I dengan morning sickness di Poliklinik Kebidanan BPK RSUZA Banda Aceh.

\section{Hubungan Antara Tingkat Pendidikan Dengan Morning Sickness}

Berdasarkan data pada tabel 7 dapat dilakukan analisa tentang hubungan antara tingkat pendidikan dengan morning sickness pada ibu hamil di Poliklinik Kebidanan BPK RSUZA Banda Aceh, yaitu dengan memasukkan hasil kategori responden ke dalam tabel kontigensi. Selanjutnya tabel kontigensi tersebut dianalisa dengan menggunakan formula chi-square test $\left(\chi^{2}\right)$ dengan tingkat kemaknaan $(\alpha) 0,05$ dan derajat kebebasan (df) 2. Hasil analisa statistik untuk melihat hubungan tersebut di atas dapat dilihat pada tabel kontigensi 3 × 2 berikut:

Tabel 11. Distribusi morning sickness berdasarkan pendidikan Di Poliklinik Kebidanan BPK RSUZA Banda Aceh 2007

\begin{tabular}{|c|c|c|c|}
\hline \multirow{3}{*}{ Pendidikan } & \multicolumn{2}{|c|}{$\begin{array}{l}\text { Tingkat morning } \\
\text { sickness }\end{array}$} & \multirow{3}{*}{ Jumlah } \\
\hline & & Tidak & \\
\hline & M.S & M.S & \\
\hline Rendah & $3(1,83)$ & $2(3,16)$ & 5 \\
\hline Menengah & $4(2,93)$ & $4(5,06)$ & 8 \\
\hline Tinggi & $4(6,23)$ & $13(10,76)$ & 17 \\
\hline Jumlah & 11 & 19 & 30 \\
\hline
\end{tabular}

Dari tabel 11 diketahui nilai $\chi^{2}$ hitung adalah 3,18680. Selanjutnya dilakukan pengujian hipotesa dimana tabel dengan = 0,05 dan $\mathrm{df}=2$ adalah 5,991. Perbandingan antara kedua nilai tersebut, diperoleh hasil hitung $(3,18680)<$ tabel $(5,991)$. Sehingga dapat diketahui bahwa hipotesa kerja (Ho) diterima yang berarti tidak ada hubungan yang bermakna antara tingkat pendidikan ibu hamil trimester I dengan morning sickness di 
Poliklinik Kebidanan BPK RSUZA Banda Aceh.

\section{Hubungan Antara Pendapatan Dengan Morning Sickness}

Berdasarkan data pada tabel 8 dapat dilakukan analisa tentang hubungan antara pendapatan dengan morning sickness pada ibu hamil trimester I di Poliklinik Kebidanan BPK RSUZA Banda Aceh, yaitu dengan memasukkan hasil katagori responden ke dalam tabel kontigensi. Selanjutnya tabel kontigensi tersebut dianalisa dengan menggunakan formula chi-square test () dengan tingkat kemaknaan () 0,05 dan derajat kebebasan (df) 1. Hasil analisa statistik untuk melihat hubungan tersebut di atas dapat dilihat pada tabel kontigensi $3 \times 2$ berikut:

Tabel 12. Distribusi morning sickness berdasarkan tingkat pendapatan di Poliklinik Kebidanan BPK RSUZA Banda Aceh 2007

\begin{tabular}{cccc}
\hline \multirow{2}{*}{ Umur } & \multicolumn{2}{c}{$\begin{array}{c}\text { Tingkat morning } \\
\text { sickness }\end{array}$} & \multirow{2}{*}{ Jumlah } \\
\cline { 2 - 3 } & M.S & Tidak M.S & \\
\hline Rendah & $5(2,56)$ & $2(4,43)$ & 7 \\
Sedang & $3(3,66)$ & $7(6,33)$ & 10 \\
Tinggi & $3(4,76)$ & $10(8,23)$ & 13 \\
\hline Jumlah & 11 & 19 & 30 \\
\hline
\end{tabular}

Dari tabel 12 diketahui nilai $\chi^{2}$ hitung adalah 5,04925. Selanjutnya dilakukan pengujian hipotesa dimana tabel dengan $=$ 0,05 dan $\mathrm{df}=2$ adalah 5,991. Perbandingan antara kedua nilai tersebut, diperoleh hasil hitung $(5,04925)<$ tabel $(5,991)$. Sehingga dapat diketahui bahwa hipotesa kerja (Ho) diterima yang berarti tidak ada hubungan yang bermakna antara pendapatan ibu hamil trimester I dengan morning sickness di Poliklinik Kebidanan BPK RSUZA Banda Aceh.

\section{Hubungan Antara Pekerjaan Dengan Morning Sickness}

Tabel 13. Distribusi morning sickness berdasarkan pekerjaan di Poliklinik Kebidanan BPK RSUZA Banda Aceh 2007

\begin{tabular}{cccc}
\hline \multirow{2}{*}{ Umur } & \multicolumn{2}{c}{$\begin{array}{c}\text { Tingkat morning } \\
\text { sickness }\end{array}$} & \multirow{2}{*}{ Jumlah } \\
\cline { 2 - 3 } & M.S & Tidak M.S & \\
\hline $\begin{array}{l}\text { Bekerja } \\
\text { Tidak } \\
\text { bekerja }\end{array}$ & $2(5,86)$ & $14(10,13)$ & 16 \\
\hline \multicolumn{1}{c}{ Jumlah } & 11 & 19 & 14 \\
\hline
\end{tabular}

Dari tabel 13 diketahui nilai $\chi^{2}$ hitung adalah 8,72443 . Selanjutnya dilakukan pengujian hipotesa di mana tabel dengan = 0,05 dan $\mathrm{df}=1$ adalah 3,841. Perbandingan antara kedua nilai tersebut, diperoleh hasil hitung $(8,72443)>$ tabel $(3,841)$. Sehingga dapat diketahui bahwa hipotesa kerja (Ho) ditolak yang berarti tidak ada hubungan yang bermakna antara pekerjaan ibu hamil trimester I dengan morning sickness di Poliklinik Kebidanan BPK RSUZA Banda Aceh.

\section{Hubungan Antara Umur Ibu Hamil Trimester I Dengan Morning Sickness}

Hasil penelitian menunjukkan bahwa demografi ibu hamil trimester I di Poliklinik Kebidanan BPK RSUZA Banda Aceh sebagian besar adalah ibu yang berumur dewasa awal (80\%) dan hasil uji statistik menunjukkan bahwa hipotesa kerja (Ho) ditolak yang berarti ada hubungan yang bermakna antara umur dengan morning sickness pada ibu hamil trimester I di Poliklinik Kebidanan BPK RSUZA Banda Aceh.

Menurut Wong (dikutip dari Potter \& Perry, 1997), usia atau umur merefleksikan kemampuan perkembangan dalam belajar dan berbagai jenis cara belajar disesuaikan dengan perkembangan (usia).

Menurut BKKBN (2006), usia untuk hamil dan melahirkan adalah 20 sampai 30 
tahun, lebih atau kurang dari usia tersebut adalah beresiko. Secara umum, seorang perempuan dikatakan siap secara fisik jika telah menyelesaikan pertumbuhan tubuhnya, yaitu sekitar usia 20 tahun. Sehingga usia 20 tahun bisa dijadikan pedoman kesiapan fisik.

Pada usia remaja seorang wanita sedang mengalami perubahan fisik dan mental menuju seorang dewasa yang bertanggung jawab, percaya pada diri sendiri, bebas dan ingin mandiri. Proses ini memerlukan waktu bertahun-tahun hingga cukup dewasa sehingga usia remaja seorang wanita belum siap fisik dan mental menjadi ibu rumah tangga. Dari sudut kesehatan obstetrik, hamil pada usia lebih muda (di bawah 20 tahun) berarti hamil dengan resiko tinggi. Komplikasi yang mungkin terjadi pada ibu dan anak seperti anemia, preeklampsia, eklampsia, abortus, partus prematurus, kematian perinatal, perdarahan dan tindakan operasi obsterik lebih sering dibandingkan dengan golongan usia 20 tahun ke atas (Sanie \& Suryadi, 1987).

Masa paling berat bagi beban psikis ibu hamil terjadi di trimester pertama, yakni ketika perubahan aktivitas hormonal ibu sedang besar-besarnya. Perubahan inilah yang dapat dengan mudah memengaruhi stabilitas emosi ibu, selain menyebabkan keluhan mualmuntah terutama di pagi hari selama dua bulan pertama. Akibatnya, beban psikologis semakin bertambah (Adelaar, 2007).

Makin tua umur ibu maka semakin terbuka pula sikapnya. Hal ini dapat dimengerti karena pengaruh lingkungan yang masih agak tepat pada golongan usia di atas 35 tahun dibandingkan usia ibu di bawah 35 tahun.

Hal ini menunjukkan bahwa umur sangat berpengaruh terhadap morning sickness yang dialami oleh sebagian besar ibu hamil. Meskipun morning sickness bisa terjadi pada umur berapa pun, tapi gejala ini lebih banyak dirasakan oleh ibu hamil yang berumur dewasa awal. Hal ini bisa terlihat dengan besarnya jumlah responden pada kategori umur dewasa awal, yaitu berjumlah 24 orang.
Jadi secara umum didapatkan kesamaan antara teori dan hasil penelitian yaitu umur, berpengaruh besar terhadap morning sickness yang dialami oleh ibu hamil trimester I.

\section{Hubungan Antara Tingkat Pendidikan Ibu Hamil Trimester I Dengan Morning Sickness}

Hasil penelitian menunjukkan bahwa sebagian besar ibu hamil trimester I yang berkunjung ke Poliklinik Kebidanan BPK RSUZA Banda Aceh berpendidikan tinggi $(56,66 \%)$ dan uji statistik menunjukkan bahwa hipotesa kerja (Ho) diterima yang berarti tidak ada hubungan yang bermakna antara pendidikan dengan morning sickness pada ibu hamil trimester I di Poliklinik Kebidanan BPK RSUZA Banda Aceh.

Pendidikan merupakan upaya manusia secara sadar tujuannya bersifat ganda yaitu menembangkan kepribadian dan kemampuan manusia di mana semakin tinggi pendidikan seseorang diharapkan semakin baik perkembangan kemampuannya (Kamars, 1998).

Pendidikan adalah variabel yang mempunyai peran cukup penting terhadap seseorang terutama dalam mengambil keputusan terhadap suatu masalah. Pada penelitian ini, sebagian besar $(56,66 \%)$ responden berpendidikan, yaitu tamat D III atau Perguruan Tinggi. Tapi karena morning sickness merupakan gejala yang wajar terjadi pada setiap ibu hamil, terutama pada ibu yang pertama kali hamil, maka meski pun kebanyakan responden berpendidikan tinggi, tak menutup kemungkinan bagi ibu hamil untuk mengalami mual dan muntah di pagi hari.

Hal ini menunjukkan bahwa pendidikan formal bukan faktor yang memengaruhi terjadinya morning sickness pada ibu hamil. Ibu hamil baik yang berpendidikan tinggi maupun rendah bisa saja mengalami morning sickness. 
Hubungan Antara Tingkat Pendapatan Ibu Hamil Trimester I Dengan Morning Sickness

Berdasarkan hasil penelitian menunjukkan bahwa sebagian besar ibu hamil trimester I yang berkunjung ke Poliklinik Kebidanan BPK RSUZA Banda Aceh berpendapatan tinggi $(43,33 \%)$ dan hasil uji statistik menunjukkan tidak ada hubungan yang bermakna antara pendapatan dengan morning sickness pada ibu hamil trimester I di Poliklinik Kebidanan BPK RSUZA Banda Aceh.

Kesiapan ibu dilihat dari segi ekonomi menjadi salah satu penentu dalam proses kehamilan yang sehat. Keluarga dengan ekonomi yang cukup dapat memeriksakan kehamilannya secara rutin dan bisa merencanakan segala sesuatunya dengan baik sejak awal.

Suatu hal yang penting adalah seseorang dengan penghasilan tinggi biasanya akan sangat berpangaruh dalam memperoleh pelayanan kesehatan namun harus didukung pula oleh faktor lainnya seperti dukungan keluarga terhadap pemenuhan kesehatan.

Ditinjau dari tingkat pendapatan, maka kebanyakan keluarga responden berpendapatan tinggi $(43,33 \%)$. Hal ini menunjukkan bahwa pendapatan keluarga bukan faktor yang memengaruhi terjadinya morning sickness pada ibu hamil. Seperti halnya pendidikan, maka morning sickness bisa terjadi pada siapapun tanpa memandang sang ibu berasal dari golongan ekonomi mana.

\section{Hubungan Antara Pekerjaan Ibu Hamil Trimester I Dengan Morning Sickness}

Berdasarkan hasil penelitian yang terlihat dalam tabel 4, distribusi pekerjaan ibu hamil trimester I adalah: 16 orang $(53,33 \%)$ bekerja, 14 orang $(46,66 \%)$ tidak bekerja. Hal ini menunjukkan bahwa jumlah ibu hamil trimester I yang bekerja dengan yang tidak bekerja hampir sama besarnya.
Setelah dilakukan pengujian hipotesa menggunakan formula chi-square test dengan $=0,05$ dan $\mathrm{df}=1$, diperoleh nilai hitung sebesar 8,72443 sedangkan tabel adalah 3,841 . Hal ini menunjukkan bahwa hipotesa kerja (Ho) ditolak yang berarti ada hubungan yang bermakna antara pekerjaan dengan morning sickness pada ibu hamil trimester I di Poliklinik Kebidanan BPK RSUZA Banda Aceh.

Saat ini, partisipasi dan peran wanita dalam pembangunan semakin besar, sehingga banyak wanita yang bekerja. Kehamilan bukanlah merupakan halangan dalam bekerja asalkan dikerjakan dengan pengertian sedang hamil. Selama hamil, yang penting tetap memperhatikan hal-hal yang dapat membahayakan kehamilanya (Royston, 1990).

Grath, dalam Abraham \& Senley (1997), menyebutkan bahwa stress yang dialami oleh pekerja lebih besar dibandingkan dengan orang yang tidak bekerja. Apalagi bila pekerjaan tersebut tidak sesuai dengan minat, bakat sereta hobinya, sehingga cenderung menganggap pakerjaan sebagai sebuah beban. Dalam melakukan pekerjaan, bila tanggung jawab berubah maka tingkat stress juga akan berubah.

Hamil adalah momen menyenangkan bagi seorang perempuan. Tapi menghadapi kesibukan kerja yang akhirnya bisa memperberat morning sickness, kondisi ini bisa menjadi persoalan. Maka, seorang ibu hamil perlu menyiasati agar kehamilannya tidak mengganggu aktivitas bekerja, atau sebaliknya, aktivitasnya tidak menganggu proses kehamilannya. Hal ini sesuai menurut Mansjoer (2001), di mana salah satu faktor yang memengaruhi terjadinya morning sickness adalah dipicu oleh kecemasan dan emosi.

\section{KESIMPULAN DAN SARAN}

Hasil penelitian kategori umur ibu yang paling banyak adalah dewasa awal yaitu sebanyak 24 orang (80\%), kategori tingkat 
pendidikan ibu yang paling banyak adalah tingkat tinggi yaitu sebanyak 17 orang $(56,66 \%)$, kategori pendapatan keluarga yang paling banyak adalah pendapatan tinggi yaitu sebanyak 13 orang $(43,33 \%)$ dan kategori pekerjaan yang terbanyak adalah ibu-ibu yang bekerja yaitu 16 orang (53,33\%). Kategori morning sickness yang terbanyak adalah tidak morning sickness yaitu sebanyak 19 orang $(63,33 \%)$. Dari hasil uji statistik terhadap umur responden, didapat hipotesa kerja (Ho) ditolak yang berarti ada hubungan bermakna antara umur ibu hamil trimester I dengan morning sickness di Poliklinik Kebidanan BPK RSUZA Banda Aceh. Dari hasil uji statistik terhadap pendidikan responden, didapat hipotesa kerja (Ho) diterima yang berarti tidak ada hubungan bermakna antara pendidikan ibu hamil trimester I dengan morning sickness di Poliklinik Kebidanan BPK RSUZA Banda Aceh. Dari hasil uji statistik terhadap pendapatan responden, didapat hipotesa kerja (Ho) diterima yang berarti tidak ada hubungan bermakna antara pendapatan ibu hamil trimester I dengan morning sickness di Poliklinik Kebidanan BPK RSUZA Banda Aceh. Dari hasil uji statistik terhadap pekerjaan responden, didapat hipotesa kerja (Ho) ditolak yang berarti ada hubungan bermakna antara pekerjaan ibu hamil trimester I dengan morning sickness di Poliklinik Kebidanan BPK RSUZA Banda Aceh.

Saran yang dapat diberikan bagi perawat agar dapat memberikan informasi selengkapnya kepada ibu hamil trimester I tentang morning sickness. Bagi Rumah Sakit Umum DR Zainoel Abidin Banda Aceh agar dapat mempertahankan dan meningkatkan mutu pelayanan terhadap ibu hamil. Kepada institusi pendidikan keperawatan terutama program studi ilmu keperawatan, agar lebih meningkatkan pengetahuan kemampuan mahasiswa khususnya mengenai morning sickness. Bagi calon peneliti lain yang ingin melakukan penelitian yang berkaitan dengan morning sickness agar dapa meninjau aspek yang lain selain karakteristik ibu.

\section{DAFTAR PUSTAKA}

Abraham., Senley. 1997. Psikologi Sosial Untuk Perawatan. Edisi 1. Jakarta: EGC.

Adelaar, S.B. 2007. Trauma Kehamilan dan Pengaruhnya Pada Janin. http: // ww w. tabloidna kit a . com/ artikel.php3 ?edisi=05234\&rubrik=kecil. Diakses pada 15 Maret 2007.

Anonymous. 2006. Atasi Mual Muntah Pada Ibu Hamil Lewat Pola Makan. http:// ww w . t a b loidna ki t a . com/ artikel2.php3?edisi=06298\&rubrik=klinikibu. Diakses pada 15 Maret 2007.

Anonymous. 2006. Penanganan Morning Sickness. www.sehatgroup.web.id. Diakses pada 15 Maret 2007.

Anonymous. 2006. Kehamilan. http:// id.wikipedia.org/wiki/kehamilan. Diakses pada 15 Maret 2007.

Anonymous. 2006. Proses Kehamilan. www.mediastore.com. akses pada 15 Maret 2007.

Anonymous. 2006. Penyebab Morning Sickness. http://www.ayahbundaonline.com. Diakses pada 15 Maret 2007.

Anonymous. 2007. Nyaman Bekerja Saat Hamil. http://riaupos.com/baru/content / view/2260/65. Diakses pada 15 Maret 2007.

Arikunto, S. 2002. Prosedur Penelitian: Suatu Pendekatan Praktek. Edisi revisi 4. Jakarta: Rineka Cipta.

Azwar, A. 1996. Pengantar Administrasi Kesehatan. Edisi 3. Jakarta: Binarupa Aksara.

Carl. 1992. Leadership Role and Management Function. Philadelphia: Lipficont.

Chamberlain, G., Dewhurst, S.J. 1994. Obstetri dan Ginekologi Praktis Jakarta: Widya Medika. 
Chandra, B. 1995. Pengantar Statitik Kesehatan. Jakarta: EGC.

Cunningham. 1995. Obstetri Williams. Jakarta: EGC.

Didinkaem. 2007. Tips Mengatasi Muntah di Awal Kehamilan. http://www halalguide.info/content/view/542/69/. Diakses pada 15 Maret 2007.

Disoebrata, M.D. 1990. Obstetri Sosial. Bandung: FK UNPAD.

Hamid, A.Y.S. 1997. Jurnal Keperawatan Indonesia. Volume Pertama. Jakarta: Universitas Indonesia.

Hamilton, P.M. 1995. Dasar-Dasar Keperawatan Maternitas. Edisi 6. Jakarta: EGC.

Jones, D.L. 2005. Setiap Wanita: Panduan Terlengkap Tentang Kesehatan, Kebidanan dan Kandungan. Jakarta: Delapratasa Publishing.

Kamars, H.M.D. 1998. Sistem Pendidikan. Jakarta: Departemen P\&K.

Kasdu, D. 2005. Solusi Problem Kehamilan. Jakarta: Puspa Swara.

Mansjoer, A. 2001. Kapita Selekta Kedokteran. Jakarta: Media Aesculapius FKUI.

Manuaba, I.B.G. 2001. Kapita Selekta Penatalaksanaan Rutin Obstetrik Ginekologik dan KB. Jakarta: EGC.

Muhiman, M. 1996. Penanggulangan Nyeri Pada Persalinan. Jakarta: FKUI.

Oakley, L.D. 1998. Social Cultural Contest of Psyciatric Nursing Care. Sixth Edition. Philadelpia: Mosby Year Book Inc.

Potter., Perry. 1997. Fundamental of Nursing. Addison Wesley Company.

Royston, E. 1989. Pencegahan Kematian Ibu Hamil. Jakarta: Binarupa Aksara.

Saifuddin, A.B. 2002. Panduan Praktis Pelayanan Kesehatan Maternal dan Neonatal. Jakarta: Bina Pustaka Sarwono Prawirohardjo.

Sanie., Suryadi. 1987. Pelacakan Dini Kehamilan Beresiko Tinggi. Laporan Penelitian Kelompok Studi Masalah
Kesehatan Masyarakat kita. Jakarta: Pusat penelitian UNIKA Atmajaya.

SekNeg RI. 2004. Undang-Undang Pendidikan Nasional. Jakarta.

Singarimbun, M., Sofian, M. 1989. Metode Penelitian Survei. Jakarta: LP3 ES.

Stoppard, M. 2005. Buku Panduan Kehamilan \& Kelahiran. Jakarta: Mitra Media Publisher.

Sudjana. 1992. Metodelogi Statistika. Bandung: Tarsido.

Suririnah. 2006. Morning Sickness dan Beberapa Penanganannya. http://www. infoibu.com/tipsinfosehat/ mualmuntah.htm. Diakses pada 15 Maret 2007.

Wesson, N. 2002. Morning Sickness: Panduan Lengkap Memahami Penyebab dan Perawatan Mual-Mual Serta Muntah ketika Hamil. Jakarta: Prestasi Pustaka Publisher.

Whaley., Wong's. 1999. Nursing Care of Infant and Children. $6^{\text {th }}$ edition. Philadelpia: Mosby Company.

Wiknjosastro, H. 2005. Ilmu Kebidanan. Cetakan ke-VII. Jakarta: Yayasan Bina Pustaka Sarwono Prawirohardjo. 